\title{
Application of metagenome analysis to characterize the molecular diversity and saxitoxin-producing potentials of a cyanobacterial community: a case study in the North Han River, Korea
}

\author{
Keon Hee Kim ${ }^{1} \cdot$ Youngdae Yoon ${ }^{1} \cdot$ Woon-Young Hong ${ }^{3}$. \\ ${\text { JaeBum } \mathrm{Kim}^{2}}^{2}$ Yung-Chul Cho ${ }^{4} \cdot$ Soon-Jin Hwang ${ }^{1}$
}

Received: 21 August 2017/Accepted: 29 December 2017/Published online: 3 February 2018

(C) The Korean Society for Applied Biological Chemistry 2018

\begin{abstract}
A wide variety of cyanobacterial species that inhabit freshwater systems are known to produce diverse toxins and off-flavor compounds during the development of environmentally harmful blooms. However, cyanobacterial community development and toxin production potential have not been well studied. In this study, we examined the taxonomic diversity and saxitoxin production potential of cyanobacteria in the water and sediments of a large river, the North Han River in South Korea, by metagenome analysis using next-generation sequencing (NGS) and molecular biological approaches, respectively. NGS revealed that the entire cyanobacterial community in the study area consisted of 39 genera and 47 species. The most abundant genera were Microcystis, Anabaena, Cyanobium, and Synechococcus, which accounted for more than $90 \%$ of the entire community. The saxitoxin production potential of the cyanobacterial community was assessed by detecting the $\operatorname{sxtA}$ and $s x t G$ genes related to saxitoxin production. Eleven $s x t A$ and $24 s x t G$ genes were identified through molecular cloning and sequencing. Phylogenic analysis revealed that three $s x t A$ genes that grouped in one phylogenic branch with Scytonema sp. were distinctly separated from the sxtA genes of Anabaena, Aphanizomenon,
\end{abstract}

Soon-Jin Hwang

sjhwang@konkuk.ac.kr

1 Department of Environmental Health Science, Konkuk University, Seoul 05029, Republic of Korea

2 Department of Biomedical Science and Engineering, Konkuk University, Seoul 05029, Republic of Korea

3 Department of Animal Biotechnology, Konkuk University, Seoul 05029, Republic of Korea

4 Department of Environmental Engineering, Chungbuk National University, Cheongju 28644, Republic of Korea
Lyngbya, and Cylindrospermopsis. Sixteen of the detected $s x t G$ genes were phylogenically similar to those of $A n$ abaena circinalis (Dolichospermum circinale), Aphanizomenon gracile, and Aphanizomenon flos-aquae. Our study demonstrates the utility of the metagenomics approach for characterizing the natural community structure of cyanobacteria containing diverse and even rare species, and the evaluation of saxitoxin-producing potential in the cyanobacterial community.

Keywords Cyanobacteria - Diversity - Genes ·

Metagenomics $\cdot$ Next-generation sequencing $\cdot$ Saxitoxin

\section{Introduction}

Globally, eutrophic freshwaters are being contaminated by harmful algal blooms, particularly those produced by cyanobacteria, as a consequence of human-induced eutrophication and climate change [1, 2]. Many cyanobacterial species produce secondary metabolites, such as toxins and off-flavor compounds, which not only deteriorate ecosystem health but also cause socioeconomic problems in water use [3-5]. Among the various toxins of algal origin, saxitoxin is known as a paralytic shellfish poison $[6,7]$. This toxin has a lower $\mathrm{LD}_{50}$ than that of other cyanotoxins, such as microcystin and anatoxin [8, 9], thereby indicating its high toxicity. Cyanobacteria known to produce saxitoxin, including Anabaena (Dolichospermum), Aphanizomenon, Cylindrospermopsis, and Lyngbya, and also produce blooms in many freshwater systems worldwide, and the potentially adverse effects of saxitoxin are increasingly impacting both ecosystem and human health [10-13]. 
Nonetheless, the cyanobacteria primarily responsible for saxitoxin production have yet to be conclusively identified, because the toxin-synthesizing mechanism of cyanobacteria is not universal. Moreover, even though a particular cyanobacterial species may possess a series of toxin-synthesizing genes, production may be strain specific $[14,15]$. Accordingly, the same cyanobacterial species can be classified as either toxic or nontoxic [16]. Furthermore, differential biosynthesis of cyanotoxins by the same cyanobacterial species in geographically isolated waterbodies has often been observed. For example, saxitoxin is produced by an Australian strain Anabaena circinalis, whereas microcystin is produced by a French strain [17]. Moreover, cylindrospermopsin and saxitoxin are produced by Cylindrospermopsis raciborskii isolated from New Zealand and Brazil, respectively. It has also been reported that Anabaena flos-aquae occurring in different lakes in Canada produces either microcystin or anatoxin [18]. These observations serve to emphasize that although some cyanotoxins are detected in certain waterbodies, it would be difficult to pinpoint the species responsible for the production of these harmful toxins. Moreover, natural cyanobacteria are very diverse, and species richness is generally governed by many rare taxa [19]. Thus, it would be necessary to identify the community diversity and to find out a specific species possessing harmful toxin production potential.

In South Korea, many freshwaters have been experiencing annual cyanobacterial blooms, including those produced by Microcystis, Anabaena, Aphanizomenon, and Oscillatoria [20-22]. Detection of microcystin has been reported in most of these blooms [23-26], although there have been no reports of saxitoxin detection. However, the possible threat of saxitoxin should not be underestimated because saxitoxin can be produced by diverse species of dinoflagellates and cyanobacteria, such as Alexandrium miutum and Anabena circinalis [27-29]. It has also been reported that saxitoxin-producing ability is dependent upon environmental conditions such as the concentrations of salt and inorganic nutrients [16]. Thus, it is reasonable to infer that saxitoxin could be produced by the cyanobacterial strains present in Korean freshwater systems in response to changes in environmental conditions.

To assess the saxitoxin-producing potentials of cyanobacteria in Korean freshwaters, it is necessary to analyze both the entire cyanobacterial community in a given environmental system and the presence of toxinsynthesizing genes such as $s x t A$ and $\operatorname{sxt} G$, the core genes for saxitoxin biosynthesis [29, 30]. Typically, cyanobacterial community analysis is performed by microscopic observation. However, it is difficult to identify the entire cyanobacterial community microscopically because some genera, particularly species of Anabaena, have highly similar cellular morphologies. Moreover, rare taxa are likely to be overlooked during such observations. Thus, in the present study, we used next-generation sequencing (NGS), which facilitates the detailed analysis of community composition, including rare taxa. The aims of this study were to characterize the molecular diversity and to evaluate the saxitoxin-producing potentials of a freshwater cyanobacterial community in order to gain an understanding of the relationship between community structure and toxin production. We accordingly examined the entire community diversity and saxitoxin production potentials of cyanobacterial samples collected from both the water and sediment of a large river system using the NGS method and PCR, respectively.

\section{Materials and methods}

\section{Cyanobacterial samples}

Cyanobacterial samples were obtained from both the water column and sediment in marginal areas of the downstream region of the North Han River $\left(37^{\circ} 34^{\prime} 12.2^{\prime \prime} \mathrm{N}\right.$, $127^{\circ} 20^{\prime} 12.2^{\prime \prime} \mathrm{E}$ ) during August 2014, which coincided with the cyanobacterial blooming period in South Korea. The cyanobacteria in water were collected by pulling a plankton net (pore size: $20 \mu \mathrm{m}$; WildCo, Florida, USA) from a depth of $1.5 \mathrm{~m}$ (total estimated volume of $104.6 \mathrm{~L}$ ). The water samples were concentrated and transferred to $200-\mathrm{mL}$ transparent polyethylene bottles, to which Lugol's solution was added to a final concentration of 5\%. Cyanobacteria in the sediment were collected from a depth of $1.7 \mathrm{~m}$ using a grab sampler (Peterson grab sampler, QT Technology, Seoul, Korea) in the same area where the water samples were collected. The topmost $3 \mathrm{~cm}$ of sediment was removed and transferred to a $100-\mathrm{mL}$ dark bottle. Both water and sediment samples were stored in dark at $4^{\circ} \mathrm{C}$ prior to analysis.

\section{Genomic DNA extraction}

The zooplankton was initially removed by filtration using a $60-\mu \mathrm{m}$ mesh, and then the filtered solution was applied to a black-polycarbonate filter (pore size: $1 \mu \mathrm{m}$; Whatman Co.) to collect the cyanobacteria but remove other bacteria, with a sequential washing with distilled water three times. The filter was applied directly to a lysis solution to disrupt the cells, and then the genomic DNA was isolated from the cell lysates using a FastDNA ${ }^{\mathrm{TM}}$ SPIN Kit (MP Biomedicals, USA). The genomic DNA of cyanobacteria in sediment samples was extracted using a genomic DNA extraction kit for soil (Macherey-Nagal, Düren, USA) following the procedures reported previously with minor modification 
[31]. Briefly, $0.5 \mathrm{~g}$ of well-mixed sediment sample was vortexed with the lysis solution and silica beads, and then the supernatant was applied to a column provided in the genomic DNA extraction kit. After washing three times, the DNA was eluted using distilled water. The concentration of extracted DNA from both water and sediment samples was determined using a nanodrop spectrophotometer (Thermo Science, USA; wavelength; $260 \mathrm{~nm}$ ).

\section{Construction of a genomic DNA library}

A DNA library of extracted DNA for shotgun metagenome analysis was constructed using an Illumina library preparation kit (Illumina Co., San Diego, USA) following the manufacturer's procedure. The genomic DNA extracted from the water samples was fragmentized by vigorous vortexing with glass beads. The DNA fragments were separated by agarose gel electrophoresis, and then, the DNA bands of less than 300 base pair (bp) were excised and purified to produce the library. The genomic DNA library was analyzed by nucleotide sequencing using the Illumina Miseq System (Illumina Co., San Diego, USA). Raw sequence data from this study have been registered to NCBI BioProject database (BioProject; https://www.ncbi. nlm.nih.gov/bioproject/) with the accession number PRJNA427611.

\section{Analysis of the cyanobacterial community}

Metagenome pipeline analysis of gene fragments was conducted following procedures reported previously. The overall process comprised the following steps: quality control, assembly, gene prediction, alignment, and taxonomic annotation. During quality control, the small fragments, after removing the primer and adapter sequences from the fragments reads, were filtered using the Trimmomatic program (version 0.31) to improve the fragment assembly efficiency $[32,33]$, and assembly procedure was performed using the MetaVelvet (version 1.2.02) programs to produce contigs $[34,35]$. Gene prediction was conducted using the FragGeneScan program (ver. 1.19) targeting the assembled complete genome [36]. Alignment of the contigs obtained from the previous steps was performed using the DIAMOND program (version 0.27) of the $\mathrm{nr}$ database (http://ncbi.nlm.nih.gov/blast/db/FASTA/nr.gz) [37]. Taxonomic annotation, the final step for metagenome analysis, was performed using a taxonomic mapping file provided by the MEGAN5 program (version 5.7.0) $[38,39]$.

To identify the cyanobacterial species in the water samples, alpha taxonomy analysis was performed by microscopic observation using a Carl Zeiss Axio Vert. A1 microscope under $400 \times$ magnification (Carl Zeiss, Roßdorf, Germany). Identification of cyanobacteria at the species level was performed based on various references [40-43].

To evaluate the saxitoxin-producing potentials of the cyanobacterial community, the presence of $s x t A$ and $s x t G$, genes related to saxitoxin synthesis, was determined by PCR using the genomic DNA obtained from both water and sediment samples as templates. Primers specific for sxtA and sxt $G$ were synthesized by Bioneer (Daejeon, Korea), and the sequences of which are listed in Table 1. The $s x t A$ and $s x t G$ genes were amplified by PCR, and PCR products were cloned into a T-blunt vector (Solgent, Daejeon, Korea). Primer amplification through PCR was performed in a serial temperature treatment with 30 cycles $\left(1 \mathrm{~min}\right.$ at $95{ }^{\circ} \mathrm{C}, 30 \mathrm{~s}$ at $95{ }^{\circ} \mathrm{C}, 1 \mathrm{~min}$ at $53-55{ }^{\circ} \mathrm{C}$ (primer annealing temperature), $1 \mathrm{~min}$ at $72{ }^{\circ} \mathrm{C}$ ) with final extension of $72{ }^{\circ} \mathrm{C}$ in $5 \mathrm{~min}$. The cloning of $s x t A$ and $s x t G$ was confirmed by PCR using the same primers as used initially. Plasmids were isolated from each colony, and the DNA sequences were determined using an ABI 3730XL DNA analyzer (Perkin-Elmer, Massachusetts, USA).

The determined sequences of saxitoxin-producing genes were applied to a BLAST search against the GenBank database of NCBI (National Center for Biotechnology Information, Maryland, USA). Additionally, cyanobacterial strains, including both coiled and straight types of Anabaena circinalis (AG40090 and AG40092) and Aphanizomenon flos-aquae (AG40091), isolated previously from the same study area [44-46], were also analyzed to determine whether saxitoxin-synthesizing genes were present in cells. The identified genes, including $26 s x t A$ and $24 s x t G$ genes that encode polyketide synthase and amidinotransferase, respectively, were aligned and analyzed. A phylogenic tree was constructed by MEGA 6.0 [47] using 9 sxtA and $13 s x t G$ genes from Alexandrium spp. as the out-group.

\section{Results}

\section{Molecular diversity of the cyanobacterial community}

The molecular diversity of cyanobacterial community in the samples was investigated by the shotgun metagenome analysis. As a result, a total of 5,237,023 reads (751,853,027 bp) were analyzed, the read length of which ranged from 100 to $301 \mathrm{bp}$. Since the rarefaction curve reached a plateau after sequencing 120,000 times, the number of reads was deemed reasonable for analyzing the diversity of species, as shown in Fig. 1. On the basis of the nucleotide sequence information obtained from shotgun metagenome analysis, contigs, defined as a set of overlapping DNA segments that together represent a consensus region of DNA, were generated through the quality control 
Table 1 Sequence information of primers used in this study

\begin{tabular}{lllc}
\hline Target gene & Type & Sequence $\left(5^{\prime}\right.$ to $\left.3^{\prime}\right)$ & Reference \\
\hline$s x t A$ & Forward & GCGTACATCCAAGCTGGACTCG & 12 \\
& Reverse & GTAGTCCAGCTAAGGCATTGC & \\
\multirow{2}{*}{$s t G$} & Forward & GCGTACATCCAAGCTGGACTCC & This study \\
& Reverse & GTAGTCCAGCTAAGGCACTTGC & \\
\hline
\end{tabular}

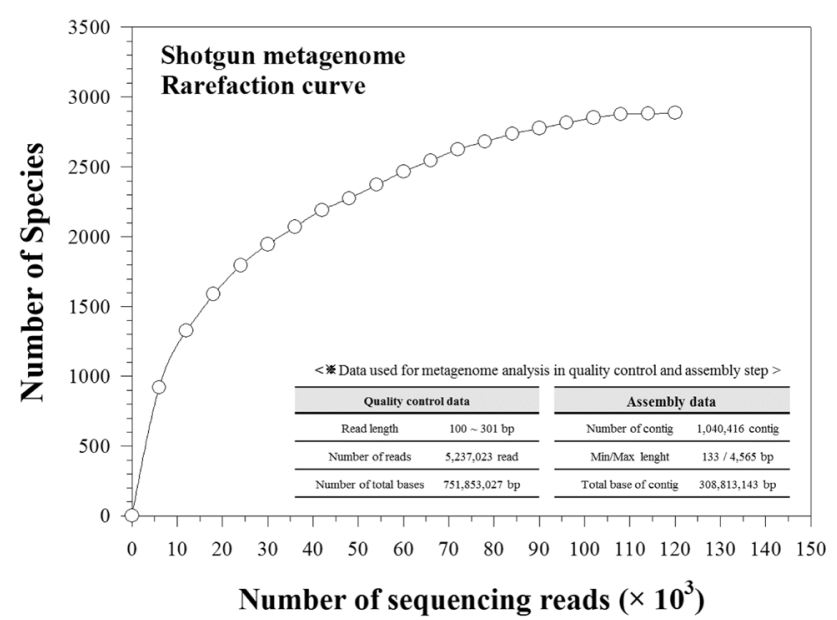

Fig. 1 Rarefaction curve from the shotgun metagenome analysis. The inset table shows the data for metagenome analysis at the quality control and assembly steps

and assembly procedures of the in silico pipeline. A total of $1,040,416$ contigs, with an average length of $315 \mathrm{bp}$, were assembled for the cyanobacterial community in the study area (Fig. 1 inset). Taxonomy classification of the assembled contigs revealed that the cyanobacterial community was composed of 39 genera, although four genera remained unclassified. The dominant genera identified were Synechococcus, Cyanobium, Anabaena (also referred to as Dolichospermum), and Microcystis, which represented $25.9,25.6,24.7$, and $16.9 \%$ of the identified genera, respectively, and collectively accounted for $93.0 \%$ of the total cyanobacterial community. At the species level, the most dominant species were Cyanobium sp. CICIAM14 (25.5\%) and Anabaena circinalis (24.6\%), followed by Microcystis aeruginosa (16.8\%) and Synechococcus rubescens (14.6\%) (Fig. 2A). In contrast with the metagenomics method, microscopic identification of cyanobacteria in the same sample revealed only three cyanobacteria, of which Anabaena spiroides (75.2\%) was the most abundant, followed by Microcystis aeruginosa (23.5\%) and Merismopedium glaucum (1.3\%) (Fig. 2B). Neither Synechococcus and Cyanobium were not observed in our microscopic observations, nor were these genera detected in previous studies of the same river system [48-52].

The failure to detect these two genera could be attributable to their very small cell size $(2-4 \mu \mathrm{m}$ in diameter) and to their morphological similarity to single cells of Microcystis. Accordingly, they might be overlooked or misidentified during microscopic observation [62]. Moreover, since Anabaena spiroides is morphologically very similar to Anabaena circinalis, it would be difficult to distinguish these two species by alpha taxonomy using microscopic observation [41]. Most of all, the difference between metagenome and microscopic analysis was manifest in rare species that accounted for less than $5 \%$ of the total population. Metagenome analysis revealed more than 20 rare cyanobacterial species during the sampling period, including Aphanizomenon flos-aquae, Prochlococcus spp. Planktothrix agardhii, Synechocystis spp., Lyngbya aestuarii, Nodularia spumigena, Scytonema hofmanii, Scytonema spp., and Cylindrospermopsis raciborskii, whereas the only rare species observed in the microscopic analysis was Merismopedium glacum (Fig. 1B). This result indicates the limitation of direct microscopic observation for rarely occurring species and emphasizes the efficiency and power of metagenomics for measuring the diversity of cyanobacterial communities.

\section{Identification of $s x t A$ and $s x t G$ in the cyanobacterial community}

Since field samples collected from the North Han River were consisted of diverse cyanobacterial species as shown in Fig. 2, it was difficult to isolate the species responsible to produce saxitoxin. In order to evaluate the saxitoxinproducing potential, the saxitoxin-producing genes including sxtA and $s x t G$ in water and sediment samples collected from the North Han River were assessed by molecular biological method, and then the genes were subsequently identified by BLAST searching in the GenBank database (NCBI) followed by DNA sequencing.

As a result, $s x t A$ and $\operatorname{sxt} G$ genes were amplified from the genomic DNA of both water and sediment samples, and it was noticed that the sediment samples were a source of relatively more saxitoxin-producing genes (Fig. 3). The PCR products shown the expected sizes were identified as sxtA and sxt $G$ from the DNA sequencing and BLAST searching. Totally 26 and 24 genes of $s x t A$ and $s x t G$ genes, respectively, were registered in GenBank, and these were isolated from various countries, including Australia, China, Japan, and Germany. The cyanobacteria registered as 
(A)

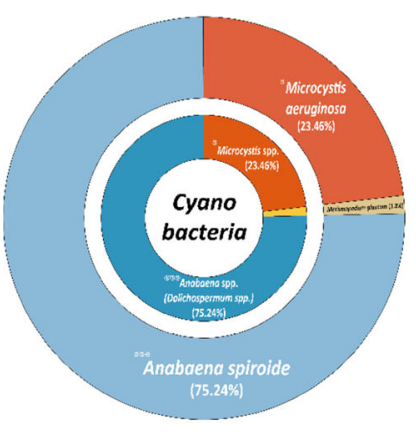

S" Reported on produce of Saxitoxin (LD50 i.p : 7.6 $\sim 10.5$ ug/kg) A Reported on produce of Anatoxin (LD50 i.p: $20 \sim 375$ ug/kg) M. Reported on produce of Microcystin (LDS0 i.p: $25 \sim 150 \mathrm{u} / \mathrm{U}$

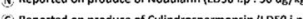
(.p. : intraperitoneal, : this study)
(B)

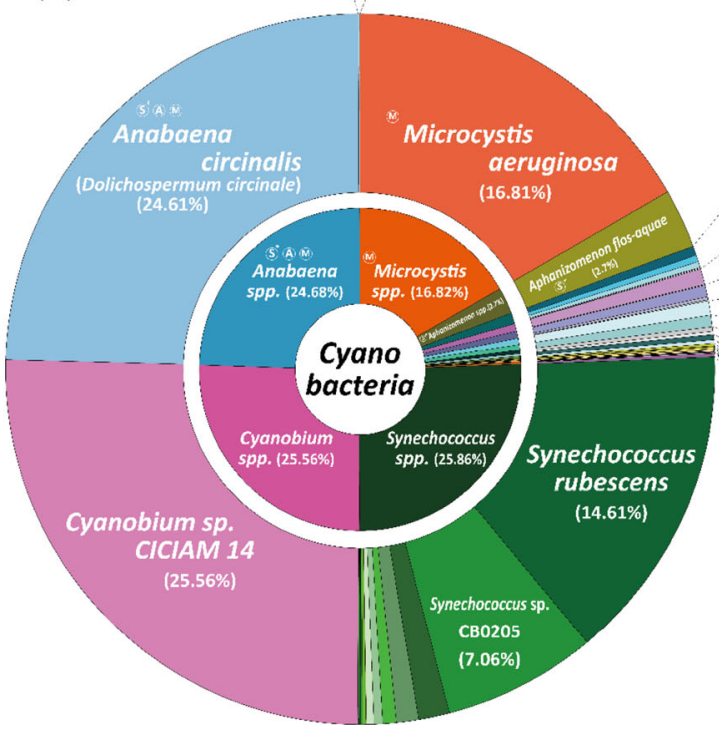

Fig. 2 Double pie charts of the cyanobacterial community in water samples from the North Han River, Korea. The inner and outer pies indicate the genus and the species compositions of the cyanobacterial community, respectively. (A) Results obtained from direct

possessing saxitoxin-synthesizing genes are in the genera Anabaena, Aphanizomenon, Cylindrospermopsis, Lyngbya, and Scytonema [21, 53-55]. From the study area in the North Han River, 11 sxtA (two clones in water and nine clones in sediment) and $24 \operatorname{sxt} G$ genes (4 clones in water and 20 clones in sediment) were identified based on database searches (Fig. 4), and these were all clustered as genes involved in cyanobacterial saxitoxin production.

\section{Phylogenetic analysis of $s x t A$ and $s x t G$}

In order to identify the saxitoxin-producing cyanobacterial species in the study area, the DNA sequences of sxtA and $s x t G$ genes were applied to phylogenetic analysis. As microscopic observation ( $\times 400$ magnification). (B) Results obtained from the shotgun metagenome genetic detection method. The nomenclature for each phylotype is based on the National Center for Biological Information (NCBI) database

shown in Fig. 4, sxtA and $s x t G$ genes from the study area were classified into phylogenic tree branches distinguished from the saxitoxin-synthesizing genes in dinoflagellates (Alexandrium spp.), a marine cyanobacteria species. Moreover, three out of $11 s x t A$ genes were grouped in one phylogenic branch with Scytonema spp., and they were distinctly separated from those of Anabaena, Aphanizomenon, Lyngbya, and Cylindrospermopsis (Fig. 4A). In case of the remaining eight $s x t A$ genes, they were classified into same branch distinguished from the majorities in the study area. It was speculated that they would come from the rare species, and those rare species should be taken into consideration for evaluating saxitoxin production potentials in the freshwater system. On the other hand, 16 of $24 s x t G$
Fig. 3 Amplification of sxtA and $s x t G$ genes from water and sediment samples collected from the North Han River, Korea. (A) The $s x t G$ gene and (B) $s x t A$ gene amplified by PCR reactions. The PCR products of $s x t G$ and $s x t A$ at approximately $200 \mathrm{bp}$ and $600 \mathrm{bp}$ respectively, were excised and cloned into a T-vector for DNA sequencing. Lane 1: DNA ladder; lane 2: water sample as a template; and lane 3: sediment sample as a template

\section{(A) sxtA: 662bp}

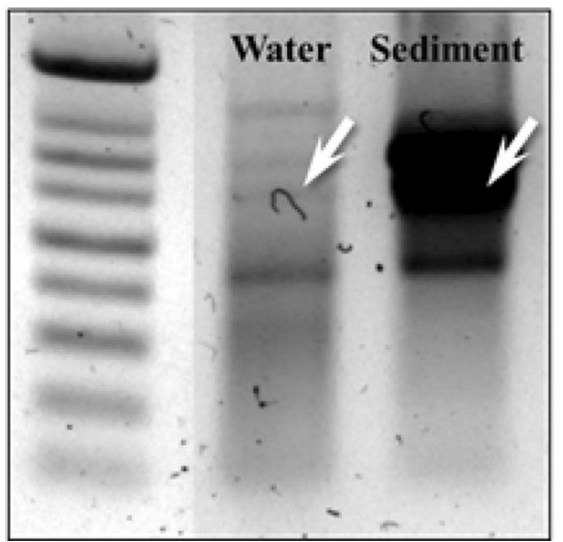

(B)

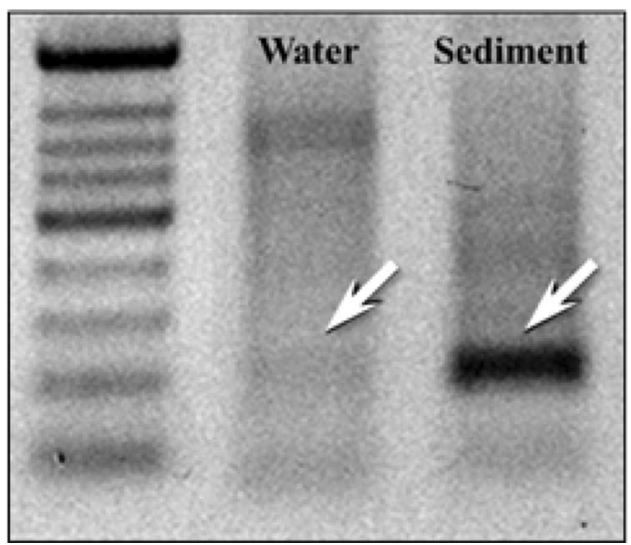



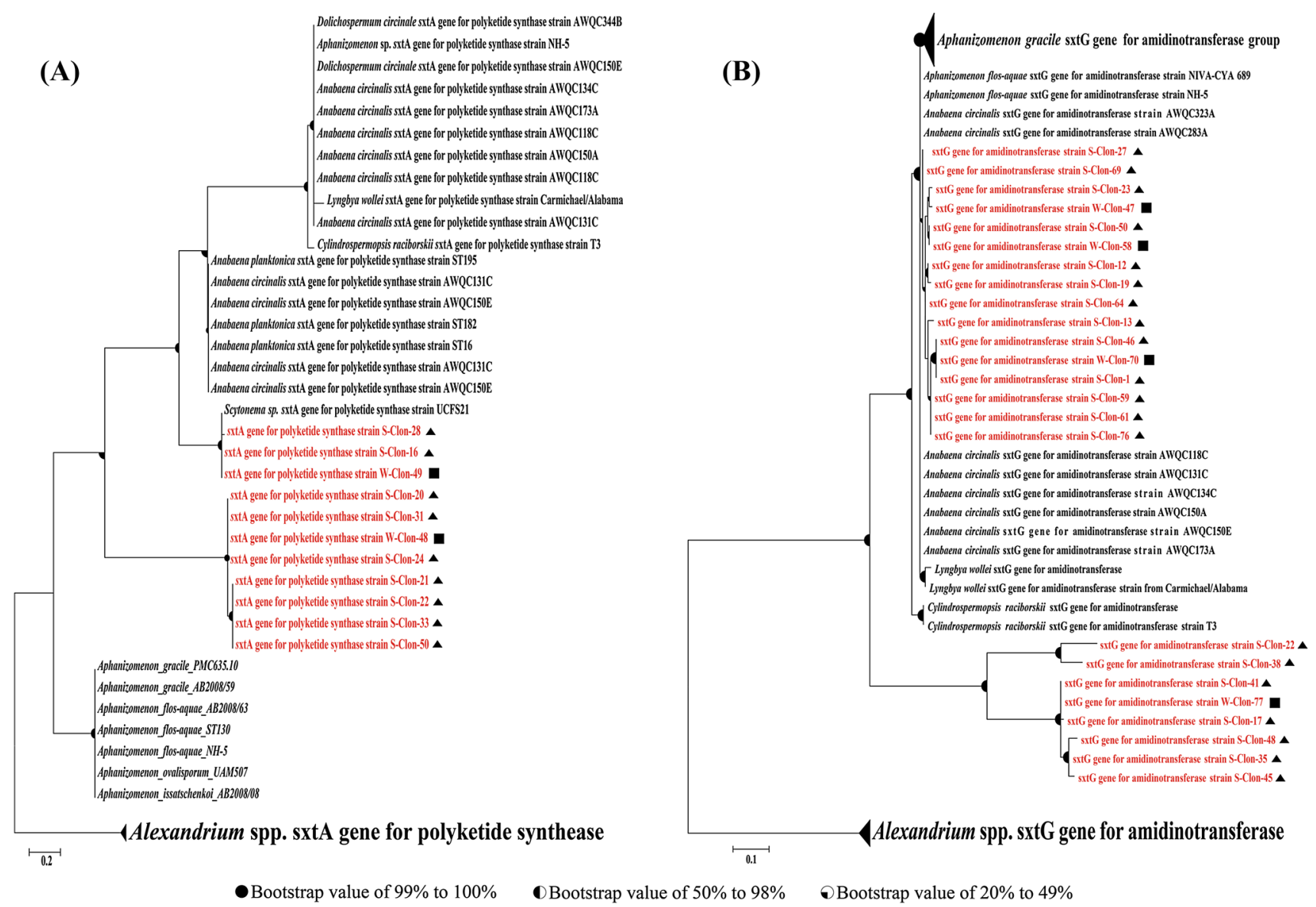

Fig. 4 Phylogenetic relationships of amidinotransferase inferred using the maximum likelihood method. The analysis was based on partial saxitoxin gene [sxtA (A), sxtG (B)] sequences (150-250 bp). $\mathrm{S}$-clone and $\mathrm{W}$-clone indicate that the taxon was sampled from the sediment (S) and water column (W), respectively. The saxitoxinproducing gene of Alexadrium spp. was used as an out-group for the

genes isolated from study area were phylogenically similar to those of Anabaena circinalis (Dolichospermum circinale), Aphanizomenon gracile, and Aphanizomenon flosaquae (Fig. 4B). However, sxt $\mathrm{G}$ gene was not detected from isolated Anabaena and Aphanizomenon species. The other eight $s x t G$ genes showed relatively low homology, $50-79 \%$, to cyanobacterial $s x t G$ genes in GenBank, and they were clustered into a single phylogenic branch. Therefore, it would be inferred that $s x t A$ and $s x t G$ genes identified in this study could be derived from the rare species. To sum up the data from molecular diversity of community and phylogenic analysis, it was concluded that Scytonema hofmanii identified in the North Han River and other rare species generally overlooked in typical analysis would be responsible for the saxitoxin production.

purpose of rooting the analysis. Bootstrap values of $20-49 \%$ are shown as a quadrisection, $50-98 \%$ are shown as a half circle, and 99-100\% are shown as a complete circle to the left of the internal nodes. Evolutionary analyses were conducted in MEGA 6.0. Square and triangle marker indicates clones detected from water and sediment sample, respectively

\section{Discussion}

Cyanobacteria in the freshwater were known to be the major producers of diverse harmful materials such as microcystin, 2-MIB, and saxitoxin. In this study, we focused on cyanobacterial community analysis by metagenomics approach and the saxitoxin-producing potentials of cyanobacterial community by molecular biological method in the North Han River, South Korea.

The metagenomics method used in this study revealed considerably higher species abundance than that revealed by microscopic observation and different percentages of the dominant species. As such, morphological similarity would be an obstacle for identifying the composition of freshwater algal communities, particularly cyanobacterial species. Indeed, the difficulties associated with alpha taxonomy have been reported with regard to identifying morphologically similar species, such as distinguishing 
between Oscillatoria agardhii and Planktothrix agardhii and between Anabaena circinalis and Anabaena crassa [40-42, 46]. Most of all, the advantageous aspects of metagenomics analysis over microscopic analysis would be the capability to detect the rare species. In fact, it was the limitation of traditional approaches to analyze cyanobacterial communities, and emphasized again the necessity of molecular approaches because the rare species should be included to evaluate the potentials of adverse effects on freshwater systems.

Among the diverse harmful toxins produced by cyanobacteria, we investigated the saxitoxin production potentials by molecular biological methods. In fact, there was no report of problem related to saxitoxin at our study sites, the North Han River in South Korea. However, there would be a possibility of saxitoxin occurrence because a wide variety of cyanobacterial species were known to produce saxitoxin, and some of them were detected from the study sites as rare species. Aphanizomenon flos-aquae, Planktothrix agardhii, Lyngbya aestuarii, and Cylindrospermopsis raciborskii detected rarely in our study sites were reported to cause blooms with saxitoxin production in Australia, Europe, and USA [11, 12, 56-58]. Additionally, Scytonema cf. crispum was recently reported to produce saxitoxin in New Zealand [59]. Since microorganisms known to produce saxitoxin were well studied, the series of genes involved in saxitoxin synthesis, such as $s x t A, s x t G$, and $s x t F$, and $s x t M$, has been identified from diverse species which encode polyketide synthase, amidinotransferase, and saxitoxin transporters, respectively [29, 60, 61]. Therefore, it was rational to evaluate the saxitoxin production potentials by determining the presence of those genes in cyanobacterial community.

Our results demonstrated that even if the majority of cyanobacteria, such as Anabaena and Aphanizomenon occurring in the study area, were reportedly known as saxitoxin-producing cyanobacteria, they did not reveal the presence of saxitoxin-producing $s x t A$ and $s x t G$ genes. Thus, it was inferred that the genes to produce saxitoxin would be derived from rare species not from majorities. In fact, BLAST searches indicated $s x t A$ and $s x t G$ genes identified from the cyanobacterial community were not derived from the dominant cyanobacteria. Moreover, the phylogenic analysis revealed that three $s x t A$ genes were clustered into one phylogenic branch with Scytonema spp. and other eight genes were also distinguished from majorities. In this regard, that there have been no reports of existence of saxitoxin in the study area could be explained by the fact that Scytonema comprises only $0.77 \%$ of the cyanobacterial community. It is thus a reasonable inference that, even though Scytonema is able to synthesize saxitoxin, the amount of saxitoxin might be below the detection level of analytical methods such as HPLC. Thus, it can be assumed that the species composition of the cyanobacterial community is considerably more diverse than previously reported and that rare species overlooked in traditional studies could possess saxitoxin production potential. Although saxitoxin has not been a problem in this freshwater system to date, it remains imperative to characterize the cyanobacterial community and the species possessing saxitoxin-synthesizing genes. It was acknowledged that environmental conditions have been changing over time and that such changes could promote cyanobacterial blooms as well as an increase in species abundance. We therefore propose the necessity for continuous research and recommend obtaining nucleotide sequence information on saxitoxin-synthesizing genes in order to clarify the relationship between cyanobacterial blooms and saxitoxin production. Most importantly, we emphasize that the application of metagenomics and molecular biological methods in cyanobacterial community analysis would play a critical role in gaining a better understanding of the possible links between cyanobacterial blooms and toxin production in freshwater systems.

We demonstrated the strength and capability of metagenome analysis, which is rapid and precise, in exploring the detailed structure of an entire cyanobacterial community composed of diverse and rare species before bloom development. Moreover, we propose that saxitoxin-producing potential could be assessed by detecting the presence of $s x t A$ and $s x t G$ genes in the community. Although further studies will be necessary to identify the species possessing saxitoxin-producing potential, the findings of the present study could provide a significant context for the management of harmful cyanobacterial blooms as early warning information. To the best of our knowledge, this is the first study to characterize the molecular diversity of a freshwater cyanobacterial community using metagenomics. We accordingly believe that the introduction of molecular biological methods along with metagenome analysis will play a critical role in this research field in the future.

Acknowledgments This study was financially supported by the Basic Environmental Research Program of the Han River System (2013-2015) of the Han River Watershed Environmental Office (the Ministry of Environment, Republic of Korea). The authors are grateful to the members of Limnology Laboratory in Konkuk University for their field assistance.

\section{References}

1. Paerl HW, Hall NS, Calandrino ES (2011) Controlling harmful cyanobacterial blooms in a world experiencing anthropogenic and climatic-induced change. Sci Total Environ 409(10):1739-1745

2. Paerl HW, Fulton RS, Moisander PH, Dyble J (2001) Harmful freshwater algal blooms, with an emphasis on cyanobacteria. Sci World J 1:76-113 
3. WHO (2003) Cyanobacterial toxins: microcystin-LR in drinkingwater. Background document for development of WHO Guidelines for drinking-water quality, 2nd edn. World Health Organization, Geneva

4. EPA (2015) Drinking water health advisory for the cyanobacterial microcystin toxins. United States Environmental Protection Agency, Washington, USA

5. NSW (2015) Blue-green algae blooms: risks to fishers. D.o.P. industries, Editor

6. Humpage A, Rositano J, Bretag AH, Brown R, Baker PD (1994) Paralytic shellfish poisons from Australian cyanobacterial blooms. Mar Freshw Res 45(5):761-771

7. Pearson L, Mihali T, Moffitt M, Kellmann R, Neilan B (2010) On the chemistry, toxicology and genetics of the cyanobacterial toxins, microcystin, nodularin, saxitoxin and cylindrospermopsin. Mar Drugs 8(5):1650-1680

8. Batoréu M, Dias E, Pereira P, Franca S (2005) Risk of human exposure to paralytic toxins of algal origin. Environ Toxicol Pharmacol 19(3):401-406

9. Metcalf JS, Codd GA (2014) Cyanobacterial toxina (Cyanotoxin) in water, 2014. Foundation for Water Research, Amsterdam

10. Dos Anjos FM, Do Carmo Bittencourt-Oliveira M, Zajac MP, Hiller S, Christian B, Erler K, Luckas B, Pinto E (2006) Detection of harmful cyanobacteria and their toxins by both PCR amplification and LC-MS during a bloom event. Toxicon 48(3):239-245

11. Foss AJ, Phlips EJ, Yilmaz M, Chapman A (2012) Characterization of paralytic shellfish toxins from Lyngbya wollei dominated mats collected from two Florida springs. Harmful Algae 16:98-107

12. Ballot A, Fastner J, Wiedner C (2010) Paralytic shellfish poisoning toxin-producing cyanobacterium Aphanizomenon gracile in northeast Germany. Appl Environ Microbiol 76(4):1173-1180

13. Hoff-Risseti C, Dorr FA, Schaker FD, Pinto E, Werner VR, Fiore MF (2013) Cylindrospermopsin and saxitoxin synthetase genes in Cylindrospermopsis raciborskii strains from Brazilian freshwater. PLoS ONE 8(8):e74238

14. Moustafa A, Loram JE, Hackett JD, Anderson DM, Plumley FG, Bhattacharya D (2009) Origin of saxitoxin biosynthetic genes in cyanobacteria. PLoS ONE 4(6):e5758

15. Srivastava A, Ko SR, Ahn CY, Oh HM, Ravi AK, Asthana RK (2016) Microcystin biosynthesis and mcyA expression in geographically distinct microcystis strains under different nitrogen, phosphorus, and boron regimes. Biomed Res Int 2016:13

16. Boopathi T, Ki J-S (2014) Impact of environmental factors on the regulation of cyanotoxin production. Toxins 6(7):1951-1978

17. Chorus I, Bartram J (1999) Toxic cyanobacteria in water: a guide to their public health consequences, monitoring and management. WHO, London

18. New-Zealand Ministry of Health (2016) Guidelines for drinkingwater quality management for New Zealand. Ministry of Health, Wellington

19. Whitton BA (2012) Ecology of cyanobacteria II: their diversity in space and time. Springer, Berlin

20. Park HJ (2013) Study on harmful cyanobacteria and off-flavor production in Lake Paldang. Konkuk University, Seoul

21. Baek JS (2015) The phytoplankton community and the waterquality assessment in Paldang-Lake. Kyonggi University, Seoul

22. Kim YJ, Baek JS, Youn SJ, Kim HN, Lee BC, Park S, You KA, Lee JK (2016) Cyanobacteria community and growth potential test in sediment of lake Paldang. Journal of Korean Society on Water Environment 32:9

23. Lee HS, Oh KH, Cho YC (2008) Isolation of cyanobacteria producing microcystin from lakes. Korean J Microbiol 44(3):6
24. Kim YG, Shin YK, Choi JK (2000) Studies on the phytoplankton community in the Paldang Lake. Environ Sci Eng Center Sang-ji Univ 6:11

25. Park H-K, Jheong WH, Kwon OS, Ryu J-K (2000) Seasonal succession of toxic cyanobacteria and microcystins concentration in Paldang reservoir. Algae 15(1):29-35

26. Jheong WH (2001) Characteristics of occurrence and control of cyanobacteria and phytoplankton in Lake Paldang. Dankook University, Yongin

27. D’Agostino PM, Song X, Neilan BA, Moffitt MC (2016) Proteogenomics of a saxitoxin producing and non toxic strain of Anabaena circinalis (cyanobacteria) in response to extracellular $\mathrm{NaCl}$ and phosphate depletion. Environ Microbiol 18(2):461-476

28. Lin X, Ding H, Zeng Q (2016) Transcriptomic response during phage infection of a marine cyanobacterium under phosphoruslimited conditions. Environ Microbiol 18(2):450-460

29. Hii KS, Lim PT, Kon NF, Takata Y, Usup G, Leaw CP (2016) Physiological and transcriptional responses to inorganic nutrition in a tropical Pacific strain of Alexandrium minutum: implications for the saxitoxin genes and toxin production. Harmful Algae 56:9-21

30. D'Agostino PM, Woodhouse JN, Makower AK, Ac Yeung, Ongley SE, Micallef ML, Moffitt MC, Neilan BA (2016) Advances in genomics, transcriptomics and proteomics of toxin producing cyanobacteria. Environ Microbiol Rep 8(1):3-13

31. Lazarevic V, Gaïa N, Girard M, François P, Schrenzel J (2013) Comparison of DNA extraction methods in analysis of salivary bacterial communities. PLoS ONE 8(7):e67699

32. Bolger AM, Lohse M, Usadel B (2014) Trimmomatic: a flexible trimmer for Illumina sequence data. Bioinformatics 30(15):170

33. Mende DR, Waller AS, Sunagawa S, Järvelin AI, Chan MM, Arumugam M, Raes J, Bork P (2012) Assessment of metagenomic assembly using simulated next generation sequencing data. PLOS ONE 7(2):e31386

34. Zerbino DR, Birney E (2008) Velvet: algorithms for de novo short read assembly using de Bruijn graphs. Genome Res 18(5):821-829

35. Namiki T, Hachiya T, Tanaka H, Sakakibara Y (2012) MetaVelvet: an extension of Velvet assembler to de novo metagenome assembly from short sequence reads. Nucleic Acids Res 40(20): $155-\mathrm{e} 155$

36. Rho M, Tang H, Ye Y (2010) FragGeneScan: predicting genes in short and error-prone reads. Nucleic Acids Res 38(20):e191-e191

37. Buchfink B, Xie C, Huson DH (2015) Fast and sensitive protein alignment using DIAMOND. Nat Methods 12(1):59-60

38. Huson DH, Auch AF, Qi J, Schuster SC (2007) MEGAN analysis of metagenomic data. Genome Res 17(3):377-386

39. Huson DH, Mitra S, Ruscheweyh HJ, Weber N, Schuster SC (2011) Integrative analysis of environmental sequences using MEGAN4. Genome Res 21(9):1552-1560

40. Komárek J, Komárková J (2004) Taxonomic review of the cyanoprokaryotic genera Planktothrix and Planktothricoides. Czech Phycol 4:1-18

41. Komárek J, Zapomělová E (2007) Planktic morphospecies of the cyanobacterial genus Anabaena $=$ subg. Dolichospermum-1. Part: coiled types. Fottea 7(1):1-31

42. Komárek J, Zapomělová E (2007) Planktic morphospecies of the cyanobacterial genus Anabaena $=$ subg. Dolichospermum-2. part: straight types. Fottea 8(1):1-14

43. Felisberto SA, e Souza DBS (2014) Characteristics and diversity of cyanobacteria in periphyton from lentic tropical ecosystem, Brazil. Adv Microbiol 4(15):1076

44. HRWEMD (2012) Distribution and eco-physiological characteristics of harmful algae in North Han River. Final Report, H.R.W.a.E.M. District) 
45. HRWEMD (2013) Investigation of causes of off-flavor material production by harmful algae and management strategy. Final Report, H.R.W.a.E.M. District

46. Kim KH, Lim BJ, You KA, Park MH, Park JH, Kim KH, Hwang SJ (2014) Identification and analysis of geosmin production potential of Anabaena strain isolated from North Han River. Korean J Ecol Environ 47(4):7

47. Tamura K, Stecher G, Peterson D, Filipski A, Kumar S (2013) MEGA6: molecular evolutionary genetics analysis version 6.0. Mol Biol Evol 30(12):2725-2729

48. Han MS, Auh YY, Ryu JK, Yoo KI, Choi YK (1995) Ecological studies on Pal'tang River-reservoir system in Korea 2. Changes in phytoplankton community structure. Korean J Limnol 28:335-344

49. Hong SS, Auh YY (2002) Ecological studies on Pal'tang riverreservoir system in Korea 4. Dynamics on inorganic nutrients, POM and phytoplankton succession in the lower stream Kyungan. Korean J Ecol Environ 35(1):9

50. Han MS, Jheong WH, Park JD, Kim JM (2005) Correlation between phytoplankton dynamics and water quality in Paldang Reservoir. Korean J Limnolo 38(2):7

51. Park H, Lee HJ, Kim EK, Jung DI (2005) Characteristics of algal abundance and statistical analysis of environmental factors in Lake Paldang. J Korean Soc Water Qual 21:584-594

52. HRWEMD (2015) Investigation of causes of off-flavor material production by harmful algae and management strategy. Final Report, H.R.W.a.E.M. District, Editor

53. Casero MC, Ballot A, Agha R, Quesada A, Cirés S (2014) Characterization of saxitoxin production and release and phylogeny of sxt genes in paralytic shellfish poisoning toxin-producing Aphanizomenon gracile. Harmful algae 37:28-37

54. Kellmann R, Mihali TK, Jeon YJ, Pickford R, Pomati F, Neilan BA (2008) Biosynthetic intermediate analysis and functional homology reveal a saxitoxin gene cluster in cyanobacteria. Appl Environ Microbiol 74(13):4044-4053

55. Al-Tebrineh J, Mihali TK, Pomati F, Neilan BA (2010) Detection of saxitoxin-producing cyanobacteria and Anabaena circinalis in environmental water blooms by quantitative PCR. Appl Environ Microbiol 76(23):7836-7842

56. Beltran EC, Neilan BA (2000) Geographical segregation of the neurotoxin-producing cyanobacterium Anabaena circinalis. Appl Environ Microbiol 66(10):4468-4474

57. Mahmood NA, Carmichael WW (1986) Paralytic shellfish poisons produced by the freshwater cyanobacterium Aphanizomenon flos-aquae NH-5. Toxicon 24(2):175-186

58. Cirés S, Wörmer L, Ballot A, Agha R, Wiedner C, Velázquez D, Casero MC, Quesada A (2014) Phylogeography of cylindrospermopsin and paralytic shellfish toxin-producing Nostocales cyanobacteria from Mediterranean Europe (Spain). Appl Environ Microbiol 80(4):1359-1370

59. Smith FM, Wood SA, van Ginkel R, Broady PA, Gaw S (2011) First report of saxitoxin production by a species of the freshwater benthic cyanobacterium, Scytonema Agardh. Toxicon 57(4):566-573

60. Ongley SE, Pengelly JJ, Neilan BA (2016) Elevated $\mathrm{Na}^{+}$and $\mathrm{pH}$ influence the production and transport of saxitoxin in the cyanobacteria Anabaena circinalis AWQC131C and Cylindrospermopsis raciborskii T3. Environ Microbiol 18(2):427-438

61. Wang D-Z, Zhang SF, Zhang Y, Lin L (2016) Paralytic shellfish toxin biosynthesis in cyanobacteria and dinoflagellates: a molecular overview. J Proteom 135:132-140

62. McGregor GB (2013) Freshwater cyanobacteria of north-eastern Australia: 2. Chroococcaes (Phytotaxa 133). Magnolia Press, Auckland, p 130 